\title{
An alternative method to determine the diffusion coefficient for the shrink- ing core model
}

\author{
Sylwia Kwiatkowska-Marks*, Marek Wójcik, Leonard Kopiński \\ Faculty of Technology and Chemical Engineering Science, University of Technology and Life Sciences, Seminaryjna 3, \\ 85-435 Bydgoszcz, Poland \\ "Corresponding author: e-mail address: Sylwia.Kwiatkowska@utp.edu.pl
}

\begin{abstract}
A new method to determine the effective diffusion coefficient of sorbate in sorbent granule based on the analytical solution of the shrinking core model (SCM) has been proposed. The experimental data presented by Lewandowski and Roe ${ }^{1}$ concerning the sorption of copper ions by alginate granules have been applied to compare the analytical and numerical methods. The results obtained by both methods are very close.
\end{abstract}

Keywords: Shrinking core model, Sorption, Alginate gel, Diffusion coefficient.

\section{INTRODUCTION}

In the last several years, the studies on possibility of the wider application of shrinking core model developed by Levenspiel $^{2}$ have been carried out. Works ${ }^{3-7}$, among other, confirmed usability of the above mentioned model for more complex situations than that described by Levenspiel. Lazaridis and Charalambous ${ }^{3}$ evaluated the effective diffusion coefficients by employing the SCM model for trivalent chromium ions, which were removed from binary aqueous solutions by composite alginate-goethite beads in a batch mode. Ko et $\mathrm{al}^{4}$ investigated the sorption of copper and cadmium ions onto bone char in single component systems using fixed-bed column adsorbers. A filmpore diffusion model (based on the unreacted core model) was successfully used to predict the fixed-bed breakthrough curves for the two metal ions. In Pritzker ${ }^{5}$ work shrinking-core equation for pore diffusion control has been extended to the case of a facile heterogeneous reaction coupled to a facile homogeneous reaction occurring within the pores of the product layer and in the bulk solution. A model based on the shrinking-core principle was presented for three cases of oxidative metal leaching from nonporous mineral particles ${ }^{6}$. Several limitations inherent in the assumptions of the traditional SCM model, such as those of oxidation agent in excess and first-order irreversible kinetics, are overcome. Crundwell and Godorr ${ }^{7}$ presented a mathematical model (based on the SCM model) of the leaching of gold in cyanide solutions. In this work the authors proposed that a layer of passivating material forms on the surface of the gold particle as it dissolves.

After modification, the model can be applied to determine the effective diffusion coefficient in the processes which tend to eliminate the heavy metals from aqueous solutions in the cases when the sorption process occurs besides diffusion ${ }^{\mathbf{1}} \mathbf{8 - 1 0}$. Moreover, the SCM model can be applied in hydrometallurgy for the liquid-solid system ${ }^{11}$.

Alginic acid is a biopolymer carrying carboxyl groups capable of forming complexes with metal ion. Many studies have been carried out on the application of alginic acid to the aqueous-phase separation of heavy metals, 12-15. Deans and Dixon ${ }^{12}$ studied the efficiency of alginic acid for removing lead (II) and copper (II) ions from water. Carboxylated alginic acid prepared through oxidation reaction with potassium permanganate had a high uptake capacity of $3.1 \mathrm{mmol} / \mathrm{g}$ dry mass at $\mathrm{pH} 4$ and showed higher affinity to heavy metals compared to alkaline metals $\left(\mathrm{Ca}^{2+}, \mathrm{Mg}^{2+}\right)$ in the mixed metal system ${ }^{13}$. Removal of $\mathrm{Co}, \mathrm{Cu}$ and $\mathrm{Zn}$ was achieved by producing $\mathrm{Cu} / \mathrm{Co}$-alginate gels or $\mathrm{Cu}-\mathrm{Zn}-\mathrm{H}$-alginate gels in situ ${ }^{14,15}$. A viscous Naalginate solution was directly dispensed dropwise into the acidic aqueous media containing the dissolved copper and zinc or copper and cobalt to form spherical alginate gels which subsequently absorbed these ions until the final equilibrium was reached.

\section{CONVENTIONAL METHOD TO DETERMINE THE EFFECTIVE DIFFUSION COEFFICIENT}

According to the SCM model, effective diffusion coefficient of copper in porous granules is determined from the relationship (1) by Rao and Gupta ${ }^{16}$

$\left[1-3\left(1-X_{t}\right)^{2 / 3}+2\left(1-X_{t}\right)\right]=\frac{6 D}{C^{0} R^{2}} \int_{0}^{t} C_{t} d t$

where:

$X_{t}=\frac{C_{i}-C_{t}}{C_{i}-C_{\infty}}$

For the closed system and sorption limited by internal diffusion, assuming a quasi-steady state:

$C^{0}=\frac{\left(C_{i}-C_{\infty}\right) \cdot V}{N \cdot \frac{4}{3} \pi \cdot R^{3}}$

The values of $\int_{0}^{t} C_{t} d t$ are usually determined numerically by the trapezoidal method.

Then, the dependence between the left side of equation (1) and the calculated integral values are plotted. The value of the effective diffusion coefficient is calculated from the slope of the above plot as equation (4):

$D=\frac{[\text { slope }] \cdot C^{0} \cdot R^{2}}{6}$

The described method is very often applied to study the sorption and desorption of such elements as: copper, cobalt, chromium, nickel, lead, gold and silver $4,8,9,17$. Also Lewandowski and Roe ${ }^{1}$ took advantage of this method in their calculations. 


\section{ALTERNATIVE METHOD}

Alternative to the conventional method for the calculation of the effective diffusion coefficient (let us name it numerical method) is the analytical method. The difference between the analytical and numerical methods consists in the manner of the solution of the equation (1) describing the process of metal sorption in granule. In the numerical method, the integral is calculated by applying the numerical trapezoidal method however, the analytical method consists in analytical integration. The starting point in both methods was the differential equation ${ }^{\mathbf{1 6}}$ describing radius $r_{c}$ (unreacted core) change of the unreacted part in granule progressing in time:

$-C^{0} r_{c}^{2} \frac{d r_{c}}{d t}\left(\frac{1}{r_{c}}-\frac{1}{R}\right)=D C_{t}$

By applying a suitable substitution, Rao and Gupta ${ }^{\mathbf{1 6}}$ obtained the following equation:

$-\frac{C^{0}}{D} \int_{R}^{r_{c}}\left(\frac{1}{r_{c}}-\frac{1}{R}\right) r_{c}^{2} d r_{c}=\int_{0}^{t} C_{t} d t$

After the integration of the left side of equation (6) and rearrangement, equation (1) is obtained.

Otherwise, after rearrangement of equation (5), we obtain:

$\frac{d r_{c}}{d t}=-\frac{R D C_{t}}{C^{0} r_{c}\left(R-r_{c}\right)}$

Radius $r_{c}$ to granule radius $R$ ratio is described by relationship: $\left[1-\left(\frac{r_{c}}{R}\right)^{3}\right]=X$, simultaneously: $X_{t}=\frac{C_{i}-C_{t}}{C_{i}-C_{\infty}}$ therefore:

$C_{t}=C_{i}-\left[1-\left(\frac{r_{c}}{R}\right)^{3}\right]\left(C_{i}-C_{\infty}\right)$

After substituting Eq. (8) to Eq. (7), integration and rearrangement, we obtain:

$t=\frac{C^{0} \cdot R^{2}}{D\left(C_{i}-C_{\infty}\right)} \int_{r_{c}}^{R} \frac{R r_{c}-r_{c}^{2}}{\frac{C_{\infty} \cdot R^{3}}{\left(C_{i}-C_{\infty}\right)}+r_{c}^{3}} d r_{c}$

By integration of the integral occurring in Eq. (9), the following relationship is obtained:

$t=\frac{C^{0} R^{2}}{D\left(C_{i}-C_{\infty}\right)}\left\{\frac{1}{3} \cdot \ln \left(\frac{\chi^{3}+\omega^{3}}{\chi^{3}+1}\right)+\frac{1}{6 \chi} \cdot \ln \left[\frac{\left(\chi^{2}-\chi+1\right)(\chi+\omega)^{2}}{(\chi+1)^{2}\left(\chi^{2}-\chi \omega+\omega^{2}\right)}\right]+\right.$

$\left.+\frac{1}{\chi \sqrt{3}}\left[\arctan \left(\frac{2-\chi}{\chi \sqrt{3}}\right)-\arctan \left(\frac{2 \omega-\chi}{\chi \sqrt{3}}\right)\right]\right\}$

where:

$\chi=\left(\frac{C_{\infty}}{C_{i}-C_{\infty}}\right)^{1 / 3}$

and:

$\omega=\left(\frac{C_{t}-C_{\infty}}{C_{i}-C_{\infty}}\right)^{1 / 3}=\frac{r_{c}}{R}$
In order to calculate the effective diffusion coefficient, first of all, for the given values of time $t$ and for the known $C_{i}$ and $C_{\infty}$ values, $P(\omega)$ is calculated as follows:

$$
\begin{aligned}
& P(\omega)=\left\{\frac{1}{3} \cdot \ln \left(\frac{\chi^{3}+\omega^{3}}{\chi^{3}+1}\right)+\frac{1}{6 \chi} \cdot \ln \left[\frac{\left(\chi^{2}-\chi+1\right)(\chi+\omega)^{2}}{(\chi+1)^{2}\left(\chi^{2}-\chi \omega+\omega^{2}\right)}\right]+\right. \\
& \left.+\frac{1}{\chi \sqrt{3}}\left[\arctan \left(\frac{2-\chi}{\chi \sqrt{3}}\right)-\arctan \left(\frac{2 \omega-\chi}{\chi \sqrt{3}}\right)\right]\right\}
\end{aligned}
$$

Then, a graph of relationship: $P(\omega)=f(t)$ is plotted. Effective diffusion coefficient $D$ is calculated from the slope of the above plot as equation (14):

$D=\frac{[\text { slope }] \cdot C^{0} \cdot R^{2}}{\left(C_{i}-C_{\infty}\right)}$

\section{RESULTS AND DISCUSSION}

For the determination of the diffusion coefficient of copper ions in alginate granules by analytical method, we made use of the data presented by Lewandowski and Roe'

The dependence between $P(\omega)$ values and time, taking into account the content of alginate in granules determined for the diffusion of $\mathrm{Cu}$ (II) ions is presented in Fig.1. Biopolymer content in the beads was varied between $2 \%$ and $5 \% \mathrm{w} / \mathrm{w}$. It can be clearly seen that the points lay along the straight lines, and all correlation coefficients are greater than 0.99 .

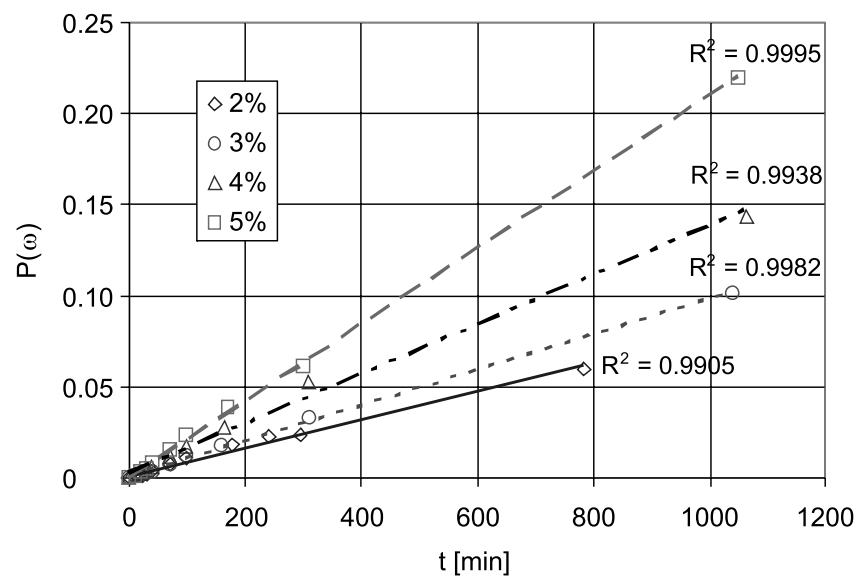

Figure 1. Dependence between $P(\omega)$ values and time for various contents of alginate in granules determined for the diffusion of $\mathrm{Cu}$ (II) ions

The obtained results were compared with the results determined by the numerical method by Lewandowski and Roe $^{1}$ (Table 1).

Table 1. Effective diffusion coefficient of $\mathrm{Cu}(\mathrm{II})$ ions in calcium alginate granules with various content of biosorbent

\begin{tabular}{|l|c|c|}
\hline \multirow{2}{*}{$\begin{array}{l}\text { Content of alginate } \\
{[\% \mathrm{wt}]}\end{array}$} & \multicolumn{2}{|c|}{$D \cdot 10^{5}\left[\mathrm{~cm}^{2} / \mathrm{s}\right]$} \\
\cline { 2 - 3 } & numerical method & analytical method \\
\hline 2 & 0.89 & 0.82 \\
\hline 3 & 0.98 & 0.98 \\
\hline 4 & 1.47 & 1.47 \\
\hline 5 & 1.84 & 1.84 \\
\hline
\end{tabular}




\section{CONCLUSIONS}

It was shown that the analytical method can be effectively applied instead of the numerical method in order to calculate the effective diffusion coefficient. The results obtained by both methods are very similar.

\section{NOMENCLATURE}

$C_{t}$ - Concentration of sorbate ions in the solution in moment $\mathrm{t}$,

$C_{i} \quad$ - Initial concentration of sorbate ions in the solution,

$C_{\infty}-$ Equilibrium concentration of sorbate ions in the solution,

$C^{0}-$ Mean density of sites bonding sorbate ions in the sorbent granule,

$D$ - Effective diffusion coefficient of sorbate in the sorbent granule,

$N \quad$ - Number of the sorbent granules,

$r_{c}$ - Radius of the unreacted sorbent core,

$R \quad$ - Radius of the sorbent granules,

$t \quad-$ Time,

$V \quad$ - Volume of the solution containing the sorbate,

$X_{t} \quad$ - Conversion of the granule defined by equation (2),

$\chi \quad$ - Dimensionless constant defined by equation (10),

$\omega-$ Dimensionless constant defined by equation (11),

\section{LITERATURE CITED}

1. Lewandowski, Z. \& Roe, F. (1994). Communication to the Editor. Diffusivity of $\mathrm{Cu}^{2+}$ in Calcium Alginate Gel Beads: Recalculation. Biotechnol. Bioeng. 43, 186-187. DOI: 10.1002/bit.260430213.

2. Levenspiel (1972). Chemical Reaction Engineering, Second ed. John Wiley \& Sons, Inc., New York, 361-373.

3. Lazaridis, N.K. \& Charalambous, Ch. (2005). Sorptive removal of trivalent and hexavalent chromium from binary aqueous solutions by composite alginate-goethite beads. Water Res. 39, 4385-4396. DOI:10.1016/ j.watres.2005.09.013.

4. Ko, D.C.K., Porter, J.F. \& Mckay, G. (2001). Filmpore diffusion model for the fixed-bed sorption of copper and cadmium ions onto bone char. Water Res. 35, 38763886.DOI:10.1016/S0043-1354(01)00114-2.

5. Pritzker, M.D. (1996). Shrinking core model for systems with facile heterogeneous and homogeneous reactions. Chem. Eng. Sci. 51, 3631-3645. DOI:10.1016/00092509(95)00403-3.

6. Lapidus, G. (1992). Mathematical modelling of metal leaching in nonporous minerals. Chem. Eng. Sci. 47, 19331941. DOI: 10.1016/0009-2509(92)80311-Y.

7. Crundwell, F.K. \& Godorr, S.A. (1997). A mathematical model of the leaching of gold in cyanide solutions. Hydrometallurgy 44, 147-162. DOI:10.1016/S0304386X(96)00039-4.

8. Dicinoski, Greg W. \& Gahan, Lawrence R., et. al. (2000). Application of the shrinking core model to the kinetics of extraction of gold(I), silver(I) and nickel(II) cyanide complexes by novel anion exchange resins. Hydrometallurgy 56, 323-336. DOI:10.1016/S0304386X(00)00082-7.

9. Chen, B., Hui, C.W. \& Mckay, G. (2001). Film-Pore Diffusion Modeling for the Sorption of Metal Ions from
Aqueous Effluents onto Peat. Water Res. 35, 3345-3356. DOI:10.1016/S0043-1354(01)00049-5.

10. Beolchini, F., Pagnanelli, F., Toro, L. \& Veglio, F. (2003). Biosorption of copper by Sphaerotilus natans immobilised in polysulfone matrix: equilibrium and kinetic analysis. Hydrometallurgy 70, 101-112. DOI:10.1016/ S0304-386X(03)00049-5.

11. Nona, K. \& Liddell, C. (2005). Shrinking core models in hydrometallurgy: what are not being told about the pseudo-steady approximation. Hydrometallurgy 79, 6268. DOI:10.1016/j.hydromet.2003.07.011.

12. Deans, J.R. \& Dixon, B.G. (1992). Uptake of Pb(II) and $\mathrm{Cu}$ (II) by novel biopolymers. Water Res. 26, 469472. DOI:10.1016/0043-1354(92)90047-8.

13. Jeon, C., Park, J.Y. \& Yoo, Y.J. (2002). Characteristics of metal removal using carboxylated alginic acid. Water Res. 36, 1814-1824. DOI:10.1016/S00431354(01)00389-X.

14. Jang, L.K., Nguyen, D. \& Geesey, G.G. (1995). Selectivity of Alginate gel for $\mathrm{Cu}$ vs Co. Water Res. 29, 307-313. DOI:10.1016/0043-1354(94)E0090-S.

15. Jang, L.K. Nguyen, D. \& Geesey, G.G. (1999). An equilibrium model for absorption of multiple divalent metals by alginate gel under acidic conditions. Water Res. 33, 2826-2832. DOI:10.1016/S0043-1354(98)00373-X.

16. Rao, M.G., Gupta, A.K.(1982). Ion Exchange Process Accompanied by Ionic Reactions. Chem. Eng. J. 24, 181-190.

17. Arevalo, E., Rendueles, M., Fernandez, A., Rodriques, A. \& Diaz, M. (1998). Uptake of copper and cobalt in a complexing resin: shrinking-core model with two reactions fronts. Sep. Purif. Technol. 13, 37-46. DOI:10.1016/S1383-5866(97)00054-3. 